\title{
Assessment of radiation dose level in road side cooked meat in Makurdi metropolis, North Central Nigeria
}

\author{
${ }^{1}$ Aondoakaa J.K, ${ }^{2}$ Akaagerger N. and ${ }^{3}$ Gemanam S.J \\ ${ }^{1,2}$ Department of Physics, Benue State University, P.M.B 102119, Makurdi \\ Corresponding Author's Email: desbully@gmail.com
}

\begin{abstract}
Food borne illnesses may result from the consumption of food contaminated by microbial pathogens, toxic chemicals or radioactive materials. So far most studies have considered pathogenic and chemical aspect of food contamination. The study assesses the amount of radiation exposed to road side cooked meats within Makurdi metropolis. Different samples of the meat where collected in strategic locations and the Radiation Alert Inspector EXP. was used to detect the level of exposure in the meat samples. Results showed very low amount of radiation in the samples ranging between $1.9 \times 10^{-7} \pm 0.002 G y h^{-1}-2.7 \times 10^{-7} \pm 0.003 G_{y h} h^{-1}$.
\end{abstract}

Keywords: Radiation dose level, Roadside cooked meat.

\section{INTRODUCTION}

Food safety is everybody's concern, and it is difficult to find anyone who has not encountered an unpleasant moment of food borne illness at least once in the past year. Food borne diseases may be self-limiting; some can be very serious and even result to death. Food borne illnesses may result from the consumption of food contaminated by microbial pathogens, toxic chemicals or radioactive materials. Food contaminants are any substances not intentionally added to food, which are present in such food as a result of the production (including operations carried out in crop farming, animal husbandry and aquaculture), manufacture, processing, preparation, treatment, packing, packaging, transport or holding of such food or as a result of environmental contamination (WHO, 2015). Meat consumption in Nigeria cannot be over emphasized; this is evident through numerous food joints established on streets and the patronage witnessed in such road side joints. Meats are rich sources of essential and beneficial minerals needed for body morphological processes. Eating meat, a good source of proteins and fats, plays a major role in the intake of a number of nutritional and toxic trace elements in human health. Elements such as $\mathrm{Co}, \mathrm{Cr}, \mathrm{Fe}$, $\mathrm{Mn}, \mathrm{Mo}, \mathrm{Ni}, \mathrm{Se}, \mathrm{Sn}, \mathrm{V}$ and $\mathrm{Zn}$ are essential for growth; $\mathrm{Cu}$ and Ba may have beneficial effects on human health. Iron is required in the production of red blood corpuscles, oxygen transportation and the functioning of many enzymes in the organism. It also playsa significant role on vitamin A and iodine metabolism (Allen 2002).Zinc on the other hand is involved in glucose and lipid metabolism, hormone function and wound healing and it also helps in proper hair growth (Hambidge et al., 1987). Manganese is required in bone formation, fat and carbohydrate metabolism. Copper is required in normal carbohydrate and lipid metabolism and blood formation (Hambidge et al. 1987).

However, certain radioactive elements can infiltrate into the meats we consume, such radionuclides include carbon monosulfide (134CS, 137CS), and 2alkylcyclobutanones (2-ACBs) are radiolytic derivatives of triglycerides found exclusively in irradiated food. The compounds are generated proportionally to fat content of the food and the dose of absorbed radiation. In addition to the formation of potentially toxic 2-ACBs, irradiation leads to the formation of furan from ascorbic acid, fructose, sucrose, or glucose (Mercola, 2014).

Despite the fact that some elements are beneficial or essential to man; beneficial, essential and non-essential 


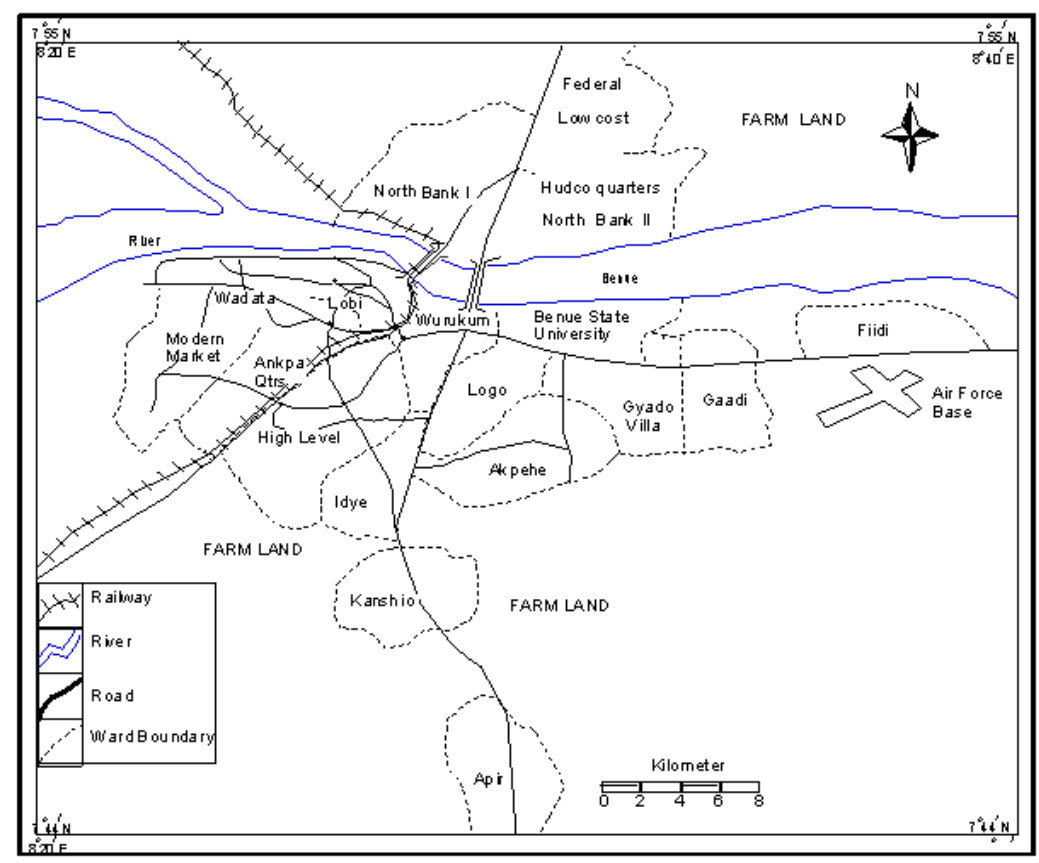

Figure1.Geographical map of Makurdi metropolis

elements can cause morphological abnormalities, reduced growth, increased human mortality rate and mutagenic effects in humans when present in excessive levels (Pier and Bang 1980; Khurshid and Qureshi 1984). Excessive accumulation of toxic metals in the human body system usually results from increased human exposure to the metals and this may cause health problems such as cancer and anaemia etc. (Li et al., 2001).Consuming food contaminated with radioactive material will increase the amount of radioactivity a person is exposed to and could increase the health risks associated with exposure to radiation. The exact impacts depend on which radionuclides have been ingested and their amount. For instance, radioactive iodine can accumulate in the human body, particularly in the thyroid gland. It has a half-life of eight days and decays naturally within weeks. As for radioactive cesium, it has a half-life as long as several decades.

In Nigeria, most road side food (meat) is exposed to an open environment. It is quite obvious that such meats are exposed to radiation which could be from the natural background, exhaust from gasoline vehicles, contaminated air or even irradiation process of food preservation.It is necessary to monitor closely the situation of food contamination by radiation on a long term basis since ingestion of food contaminated by it can pose long-term health impacts.

Therefore, research is invariably targeted at assessing the level of radiation/ or radioactive substances in meat sold on road sides within Makurdi metropolis.

\section{MATERIALS AND METHOD}

Different meat samples were collected from strategic locations within Makurdi metropolis. The locations include; International market road, Nyiman-Achusa road, Wada central Mosque Area, High level Road and North bank Road. The cooked meat samples where tagged $A$, $B, C, D, E$ and $F$ respectively representing the locations mentioned above from which they were collected. Among the meats collected was Chicken meat $(A)$, Pork meat $(B$ and $C)$, Suya (D), Fish (E) and Beef (F). These were collected as they are the most common and patronizable meats within Makurdi metropolis.

The Radiation Alert Inspector Exp. was used to measure the level of radiation in the samples. The meter was held $1-2 \mathrm{~cm}$ above the meat samples. The measurement was taken five (5) times to obtain an average result shown in table1 below. From the measured values, the absorbed dose was determined using equation 1.1

Absorbed dose rate $\left(G y h^{-1}\right)=$ Dose rate $\left(\mu S v h^{-1}\right) /\left(0.70 S v G y^{-1}\right) \times\left(10^{-3}\right)(1.1)$

Where $0.705 v G y^{-1}$ is the conversion coefficient.

Or

Absorbed dose rate $\left(G y h^{-1}\right)=$ Dose rate $\left(\mu S v h^{-1}\right) /(1000) \times\left(10^{-3}\right)$

Knowing that;

$$
1 \mu S v h^{-1}=10^{-6} G y
$$


032 Afr. J. Food Sci. Technol.

Table 1.Measured dose rate $\left(\mathrm{mRh}^{-3}\right)$

\begin{tabular}{lll}
\hline S/No. & Sample & Average dose rate $\left(m R h^{-1)}\right.$ \\
\hline 1 & A & $0.026 \pm 0.002$ \\
2 & B & $0.025 \pm 0.002$ \\
3 & C & $0.019 \pm 0.002$ \\
4 & D & $0.022 \pm 0.003$ \\
5 & E & $0.024 \pm 0.004$ \\
6 & F & $0.027 \pm 0.003$ \\
\hline
\end{tabular}

Table 2.measured dose rate $\left(\mu S \mathrm{vh}^{-2}\right)$

\begin{tabular}{lll}
\hline S/No. & Sample & Average dose rate $\left(\mu S v h^{-1}\right)$ \\
\hline 1 & A & $0.26 \pm 0.002$ \\
2 & B & $0.2 \pm 0.002$ \\
3 & C & $0.19 \pm 0.002$ \\
4 & D & $0.22 \pm 0.003$ \\
5 & E & $0.24 \pm 0.004$ \\
6 & F & $0.27 \pm 0.032$ \\
\hline
\end{tabular}

Table 3. Absorbed dose rate $\left(\mathrm{Gyh}^{-2}\right)$

\begin{tabular}{lll}
\hline S/No. & Sample & Absorbed dose rate $\left(G h^{-1}\right)$ \\
\hline 1 & A & $2.6 \times 10^{-7} \pm 0.002$ \\
2 & B & $2.5 \times 10^{-7} \pm 0.002$ \\
3 & C & $1.9 \times 10^{-7} \pm 0.002$ \\
4 & D & $2.2 \times 10^{-7} \pm 0.003$ \\
5 & E & $2.4 \times 10^{-7} \pm 0.004$ \\
6 & F & $2.7 \times 10^{-7} \pm 0.003$ \\
\hline
\end{tabular}

\section{RESULTS}

\section{DISCUSSION/ANALYSIS}

From table1, it is observed that sample $F$ which was collected from North Bank area has the highest level of radiation exposure measured to be $0.027 \pm 0.003 m R h^{-1}$, closely followed by sample $A$ (collected from the International Market road) with the average value of $0.026 \pm 0.002 m R h^{-1}$. Next is B which was measured to be0.025 $\pm 0.002 m R h^{-1}$. The table also shows sample $E$ and $D$ with an average dose rate of $0.024 \pm 0.004 m R h^{-1}$ and $0.022 \pm 0.003 \mathrm{mRh}^{-1}$ respectively falling behind sample $B$. It is observed also that sample $C$ collected from Apkehe road has the least amount of radiation $\left(0.019 \pm 0.002 m R h^{-1}\right)$.

Table 2 shows the measured dose rate in $\left(\mu S v h^{-1}\right)$. The highest level of radiation exposure observed in meat sample F, collected from North Bank, is possibly due to the geographical factors surrounding the area and also the compact nature of the area. The area is rocky and also associated with heavy vehicular activities which are possible emitters of radiation into the meat kept by the road sides. Surprisingly the meat sample collected at Akpehe Road (C) had the least amount of radiation (i.e. $\left.0.019 \pm 0.002 \mu S v h^{-1}\right)$. Due to the compact nature and heavy vehicular activities, one would expect the sample to have at least a very high amount of radiation. However the low level of radiation is attributed to the low geographical nature of Wurukum (Akpehe) area and the absence of rocks emitting background radiation.

The determined absorbed dose rates represented in table 3 ranges from $1.9 \times 10^{-7} \pm 0.002 \mathrm{Gyh}^{-1}-2.7 \times 10^{-7} \pm 0.003 \mathrm{Gyh} \mathrm{C}^{-1}$. These values are far less than those recommended by USDA-FDA (2003) between $4.5 \mathrm{kGy}$ and $7.0 \mathrm{kGy}$ maximum both for refrigerated and frozen products. Though the study did not consider distinguishing the type of radiation or radionuclide possible in the meat samples, yet the measured values are less and in compliance with the recommendations by Codex Alimentarius Commission (2011) shown in the table below.

Generally, no significant radiological impact have been observed on the surrounding environment and living population. However the research has formed a basis of 
Table 4. Codex Alimentarius Commission Guidelines Levels for Radionuclides in Foods

\begin{tabular}{l|l|}
\hline Radionuclides & Codex Guideline Level \\
\hline lodine-131 & $100 \mathrm{~Bq} / \mathrm{kg}$ \\
\hline Caesium-134 & $1,000 \mathrm{~Bq} / \mathrm{kg}$ \\
\hline Caesium-137 & $1,000 \mathrm{~Bq} / \mathrm{kg}$ \\
\hline
\end{tabular}

comparison for further research within the region since there had been no previous data showing the level of radiation contaminated in cooked meats exposed by the roadsides.

\section{CONCLUSION}

So many people are especially those in remote areas neglect the fact that food is also contaminated by radiation. Most research has considered the pathogenic and toxic chemical cause of food contamination. However it is evident that food borne illness is also as a result of contamination by radiation. Assessment of radiation level in roadside cooked meat within Makurdi metropolis shows the dose values ranging between $0.019 \pm 0.002 m R h^{-1}-0.027 \pm 0.003 m R h^{-1}$ and an absorbed dose rate between $1.9 \times 10^{-7} \pm 0.002 \mathrm{Gyh}^{-1}-2.7 \times 10^{-7} \pm 0.003 \mathrm{Gyh} h^{-1}$. Thus, it is recommended that meat generally should be preserved appropriately and cooked meat should not be exposed by the roadside but covered and packaged properly to limit contamination through radiation.

\section{ACKNOWLEDGMENT}

The research team appreciates the Management of Benue State University Makurdi especially the HOD Physics Dr M.D Tyona. The Authors are also grateful to the service of the Chief Lab Technologist Physics department and Mr. lortile Joseph of the department of radiology Benue State University Teaching Hospital Makurdi for their technical assistance.

\section{REFERENCE}

Allen LH(2002). Iron supplements: Scientific Issues Concerning Efficacy and Implementations for Res. and Programs,J. Nutr. 132(4 Suppl): 813S-9S.

Codex Alimentarius Commission (2011). Guidelines Levels for Radionuclides in Foods Contaminated.
Hambidge KM, Casey CE, Krebs NF(1987). Zinc in Trace element in Human and Animal Nutrition, Mertz W. (Ed), Academic Press: Orlando, 1-138.

https://www.foodsafety.gov.mo/e/sense/detail.aspx?id=e6c39d58-e01e45e4-9104-295a17c6a71a

Khurshid SR, Qureshi $\mathrm{IH}(1984)$. The role of inorganic elements in human body, The Nucleus, 21: 3-24.

Li XD, Poon CS, Liu PS(2001). Heavy metal contamination of urban soils and street dusts in Hong Kong. Appl. Geochem, 16: 13611368.

Mercola JM(2014). Green Med. Info: Irradiated Food Exposed to Gamma Radiation.Reviewed/Updated Friday, October 17, 2014.

Pier SM, Bang MK(1980). Environment and Health. Ann Arbor Science. Ann Arbor (MI): The Butterworth Group, 367.

United State Department of Agriculture (USDA) andU.S. Food and Drug Administration (FDA): Food Safety Guidance Document 2003.

W.H.O (2015). Food Safety: Regional Information World Health Day 2015: Food Safety 